\title{
Smallholder knowledge-practices and smallholding animals: threats or alternatives to agricultural biosecurity?
}

\section{Lewis Holloway (University of Hull) \\ Forthcoming, Journal of Rural Studies}

\begin{abstract}
This paper responds to claims that smallholders in the UK farming landscape present a biosecurity threat to commercial farming, by exploring smallholders' perspectives on animal health and their practising of biosecurity, studied through focus group research in England. Biosecurity in animal agriculture has emerged as a key research theme, with attention paid to how biosecurity is both conceptualised and practised in different farming situations. Biosecurity, as an effort to make life safe, is viewed as an articulation of political and scientific discourses with on-farm practices and particular farming and food systems. The paper draws on recent theorisation of biosecurity to discuss smallholders' engagement with the health of their animals and with biosecurity practices, and to explore their relationships with vets and commercial farmers. Contesting representations of themselves and their practices as bioinsecure, smallholders instead contend that commercial farmers and farming produce more risky disease situations, and that smallholding fosters relationships of care and response-ability more likely to engender animal health and welfare. At the same time, smallholders and farmers are involved in attempts to piece together a practical biosecurity under different pressures. The paper argues that within the complex topologies of heterogeneous farming landscapes, the 'small scale' of smallholding is constructed as problematic, and that there needs to be an acknowledgement of a politics of biosecurity in which different modes of practicing farming are debateable.
\end{abstract}

\section{Introduction}

This paper contributes to debates surrounding biosecurity in animal agriculture by focusing on smallholding as a marginal agricultural practice and smallholders as a minority group amongst farmers (Holloway, 2000). Interest in these marginal practices and farmers is high because of the concerns expressed about them in the UK as possible threats to the biosecurity of larger-scale, commercial farming. 
Biosecurity, in recent work (e.g. Bingham et al., 2008; Enticott, 2009; Hinchliffe et al., 2016), refers to a process of 'securing life', and specifically to securing or protecting the life and health of nonhuman animals, because they are valuable and/or valued for themselves, and/or because of the increasingly evident relationships between the life and health of nonhuman and human animals in the food networks they are both part of (e.g. Woods et al., 2018). This body of literature has developed nuanced conceptual understandings of biosecurity, and has explored in depth what the processes and practices of biosecurity actually become in specific empirical situations. Biosecurity, in these discussions, becomes regarded not just as a set of protocols for protecting particular forms of life. Instead it is revealed as an effect of the articulation of political and scientific discourses with the complex and sometimes problematic and contradictory knowledge-practices evident on individual farms or within farming and food systems (Hinchliffe et al., 2016).

For some UK commercial farmers, smallholders or 'hobby farmers' are represented as strong 'candidates' for bioinsecurity due to their perceived relative ignorance (Enticott, 2008a; Naylor et al., 2018). This complements a wider view in both the Global North and South that smallholder and domestic production is a threat. In South Africa, for instance, smallholder farmers were blamed for outbreaks of diseases in pigs (Mather \& Marshall, 2011) and in an urban context Hinchliffe and Bingham (2008), Hovorka (2008) and Capoccia et al. (2018) mention continuing biosecurity anxieties associated with domestic-scale or 'non-commercial' animal keeping. In the UK, this perspective is supported by the veterinary establishment (e.g. Williams \& Gillespie, 2013; Gillespie et al., 2015; Porphyre et al., 2017). Although there is some acknowledgement that some small-scale keepers do implement appropriate biosecurity measures (see, for example, Correia-Gomes et al., 2017), veterinary scientists such as Gillespie et al (2015:47) nevertheless claim that 'While disease-risk awareness and the role of biosecurity are well recognised by those working in the commercial pig sector, this may not be the case in smallholder and pet pig owners', and regard 'the pet and smallholder pig population as a potential risk for the incursion and spread of infectious disease, while highlighting the need for improved owner education'. 
The paper is thus concerned with both the practising of biosecurity on smallholdings and the argument that there is a biosecurity threat posed by smallholdings. These concerns led to the commissioning of research by the UK's Department for Environment, Food and Rural Affairs (Defra) to investigate smallholders' attitudes and practices relating to animal health, welfare and biosecurity ${ }^{1}$. The commissioning of the project can be seen as part of a governance of biosecurity by policy and other institutions, as they seek to understand the problematics of securing life in agriculture and elsewhere and devise interventions attempting to make life more secure in specific situations.

It is acknowledged at the outset that defining smallholding is problematic, with very different understandings evident in the Global North (e.g. Holloway, 2000) and Global South (e.g. McMichael, 2009). Even in the UK smallholding is highly heterogeneous, encompassing a wide range of farming practices, holding sizes, and animal species. In addition the implied opposition between 'commercial' and smallholder farmers/farming above is in practice blurred. The dualism of 'smallholding' and 'commercial' farming used in this paper is thus problematic, but reflects how the research was framed by Defra.

After reviewing recent literature on smallholding, farming knowledge-practices, human-nonhuman animal relationships in agriculture, and conceptualisations of biosecurity in animal agriculture, the paper outlines a research methodology deployed with groups of smallholders in England. I then explore some of the relationships between smallholding identities and practices, and the discourses and practising of biosecurity and farmed animal health and welfare, which the research began to reveal. In doing this it is noted that the discussions did not tend to centre around pigs and poultry (which are the species raising most concern in the literature cited above), even though these were species many smallholders kept. Pigs and poultry were referred to but the focus tended to be on sheep, as well as on other

\footnotetext{
${ }^{1}$ Agricultural policy is devolved within the UK, with separate departments existing within the Welsh, Scottish and Northern Irish legislative bodies. Defra is responsible for agriculture in England and hence this project focused on smallholding in England, which is not necessarily representative of smallholding in other parts of the UK. The project reported here, Smallholders and Animal Health and Welfare, was funded by Defra, and conducted between February and April 2016. Ethical approval for the research was awarded by the University of Hull, Department of Geography Ethics Committee in January 2016.
} 
more extensively raised species such as cattle and goats. The paper provides, then, a rather different inflection on the biosecurity issues raised. The risks associated with more 'intensive' forms of animal farming, especially pigs and poultry, have generated particular concerns in the sector and for policy makers. They are associated with more agonistic relationships between commercial farmers and smallholders because of the perceived risks posed by the latter to the former's enterprises, and have been the focus of academic attention (see, for example, Hinchliffe et al., 2016). In this paper a different perspective is taken, associated with different relationships between commercial farmers and smallholders. The paper focuses on three key areas. First, smallholding knowledge-practices are explored in a discussion of how smallholders' emergent identities as animal keepers, and the material conditions associated with their smallholdings, are associated with particular ways of caring for and about animal health, welfare and biosecurity. Second, smallholders' relationships with others implicated in the constitution of animal health, welfare and biosecurity on individual holdings are explored. Focusing on vets, these relationships can sometimes be problematic, associated with the smallholders' perceived status and the relative small scale of their operations, and with the difference that different species of animals can make. Third, smallholders' relationships with commercial farmers are discussed. The smallholders involved in the research contested representations of themselves and their holdings animals as a threat. Instead, they articulated alternative perspectives which regarded 'commercial' farmers and farming systems as in important ways more threatening to them, and to biosecurity and animal health and welfare more widely. It is these contested perspectives that, this paper argues, shed further light on the problematic construction and playing out of biosecurity in a heterogeneous farming landscape composed of very variable farm holding sizes and types, farming knowledge-practices, and discourses around 'good' biosecurity and animal health.

\section{Smallholding, Farming Knowledge-Practices and Biosecurity}

There is a minimal literature on UK smallholding, reflecting its marginal status in the countryside and in relation to 'mainstream' agriculture (Holloway, 2000; 2001; 2002). As noted, there is no clear definition of smallholding: the term is used to cover a diverse range of farming practices and holdings. The heterogeneity of smallholding has to be acknowledged. Thus Gasson (1982; 1986) and Munton et al. (1989) made 
reference to 'hobby farms' in their descriptions of changing farming landscapes, while Crouch (1997) and Halfacree (1997) have described practising small-scale farming as part of the adoption of 'alternative' rural lifestyles and counterurbanisation. For Holloway (2001:298), informed by interviews with smallholders in England and Wales, the term implied 'small scale, part-time food production, often motivated by a range of lifestyle choices involving a desire to leave a frenetic urban lifestyle in search of an imagined rural idyll'. This research demonstrated how smallholding identities were constituted around relationships with animals. As 'situated' ethical relationships (Lynn, 1998; Holloway, 2002), the humananimal relationships evident on smallholdings were characterised as different (and ethically preferable) to those which respondents argued were present in 'commercial' farming.

This work can be positioned within a wider literature on farming knowledge-practices and agricultural human-animal relationships. This literature has become an important part of 'new' animal geographies (Wolch \& Emel, 1998; Philo \& Wilbert, 2000; Urbanik, 2012), and has explored the complexities and ambiguities of humansanimal relationships in farming. Countering assumptions that farmers' views of their animals are merely instrumental, several authors have focused on the ambiguous relationships which emerge in specific farming milieus. Wilkie (2005), Riley (2011), Holloway (2001) and Convery et al. (2005) have thus described the affective or emotional relationships arising between farmers and animals which are nevertheless destined to be slaughtered, while Buller (2013) discusses the ambiguities surrounding encountering farmed animals both as individuals and as a collective 'mass' within herds or flocks. Driessen (2012) and Holloway et al (2014) have focused on the ethical views and practices of farmers which lead to situated ethical decisions being made in specific farming situations which can diverge from abstract statements about how animals should be treated due to specific on-farm conditions.

How animals are known and responded to are clearly key dimensions of the relationships explored here. Attention has been paid to the concept of 
'stockmanship'2, a form of tacit (Polanyi, 1966) or lay knowledge associated with long-term relationships with farmed animals and the acculturation of those involved into particular ways of thinking about and intervening in their lives (Burton et al., 2012; Butler \& Holloway, 2016). Drawing on the arguments of writers concerned about the displacement of farmers' local knowledge-practices by 'external' expertise (e.g. Kloppenburg, 1991), the importance of paying attention to 'lay' knowledges has been emphasised by many authors. They argue for the continued importance of such knowledges in farming systems increasingly informed by the 'expert' knowledges of agricultural scientists, advisers and so on (see, for example, Morris (2006), Riley (2008) and Tsouvalis et al. (2000) in the cases of arable agriculture and agri-environmental relationships, and Holloway (2005, see also Holloway and Morris, 2012), Enticott (2008b), Enticott and Vanclay (2011), Vanclay and Enticott (2011), Robinson (2017a) and Hinchliffe and Ward (2014), in relation to animal husbandry and disease). In these cases their embodied and locally-specific knowledges allow farmers to respond to particular issues on their farms in ways which differ from the more universal application of expert knowledge. Indeed what becomes of interest here is the interactions of these different forms of knowledge, as they complement or compete with each other (see, for example, Proctor et al., 2012), producing what Murdoch and Clark (1994) refer to as hybrid knowledges.

Related to this literature has been work on farm animal welfare (e.g. Buller \& Morris, 2003; Buller, 2009; Burton et al., 2012; Driessen, 2012; Buller \& Roe, 2018). Animal welfare in farming has tended to become codified, with farmers expected to provide certain conditions or 'freedoms' for their animals (Buller \& Morris, 2003). Countering this perspective on welfare as something which can be regulated for, are arguments favouring more 'response-able' human-animal relations. For Garlick (2015:802), drawing on Haraway (2008), this implies 'the responsiveness ("response-ability") of humans and nonhumans to the others' needs and wants', and is built on more sensuous and embodied ways of knowing the other (Brown \& Dilley, 2012). As expressed by Greenhough and Roe (2010:45), the concept of response-ability 'is about facing up to the challenge that your way of being is dependent on the suffering

\footnotetext{
${ }^{2}$ The gendered nature of this term is acknowledged. It is widely used in the field, with terms such as 'stock keeper' and 'stockwoman' used more rarely.
} 
of others ... [living] with that by seeking less painful practices and ways of being'. This argument suggests that, in different farming situations, it becomes incumbent upon farmers to become more responsive to their animals; not simply following rules but engaging in reflective practice in their relationships with their animals. An implication of this is that farming practices might diverge depending on different farming situations, while still being 'ethical'. As Driessen (2012:177) has suggested, 'defining animal welfare is not necessarily best completely relegated to a centralised policy making process, based solely on scientific expertise and abstract reductionist ethical analysis. Farmers in practice can use the variety of motives and concerns to creatively and reflexively learn to develop a system in which issues are dealt with'.

What this differentiation suggests is that animals act and are responded to in different ways on different kinds of farm: a pig or sheep is likely to be treated differently on a large commercial farm as compared to a smallholding for example, and is likely to behave and interact with people in different ways. As Holloway (2007) argues in relation to cows and automated dairy technologies, and Miele (2016) discusses in relation to sheep on an experimental farm, the idea that species have essential natures or subjectivities is countered by this argument, in which animals are instead (co)produced with the people, technologies, land and buildings constituting a farm, and with the ways in which farms are subject to specific policy and market conditions, regulatory frameworks, and so on. For Miele (2016:60), then, 'animals do not pre-exist the network that brings them into being'. From the actornetwork theory perspective she deploys it is crucial to retain an awareness of how animals are co-constituted with particular farming networks and practices. The bodies and capacities of specific animals are important to how farming is practised, as well as being the product of specific farming practices.

Alongside these conversations, there has been increasing attention paid to biosecurity in relation to farming (Enticott, 2009; Hinchliffe et al., 2016), with a series of publications exploring the concept and how it is practised in particular farming contexts. Inspired significantly by Foucault's discussions of security and biopolitics (e.g. Collier et al., 2004; Foucault, 2007), debate has centred around defining what biosecurity is, and understanding what practices are mobilized in response. Bingham et al. (2008:1528) suggest that a crude definition of biosecurity is 'making life safe', 
and that this involves an anticipation of what might happen, a preparedness to respond to the occurrence of events which threaten life, and a readiness to make interventions to reduce the risk of such events. Biosecurity thus relates to how possible futures in which life is under threat are anticipated, and pre-empted or prepared for: 'the here and now is continuously assayed for the futures that may be incubating within in and emerge out of it' (Anderson, 2010:782). Interventions conceived as promoting biosecurity thus tend to involve monitoring, regulating and preventing the movements of different forms of life, whether these are animals, plants or microbes. Notably, these interventions, which can be mundane or involve hi-tech surveillance techniques (Donaldson, 2008), take place in conditions of uncertainty, since particularly the microbial lifeforms involved evolve rapidly, and determining causal relationships between the presence of certain microbes and particular disease outbreaks is problematic: there are limits here to the extent to which 'nature' can be known and controlled (Hinchliffe, 2001; Robinson 2017b), and uncertainties afflicting both farmers and those (such as vets) who advise them (Clarke \& Knights, 2018).

As noted in writing on biosecurity (Enticott, 2008a; Hinchliffe \& Bingham, 2008; Hinchliffe \& Lavau, 2013; Hinchliffe et al., 2016), and again drawing on Foucault, farming demands the circulation of some forms of life (e.g. animals) in order to foster their reproduction and growth. Yet such circulation is problematic because undesirable, especially microbial, lifeforms are likely to circulate along with desirable ones, potentially producing disease in animals, and sometimes threatening human health. There is thus a tension between a need to permit, indeed to foster, the circulation of some forms of life, and a need to restrict, regulate or prevent the movement of others. In aiming to deal with this tension, what are presented as 'biosecurity measures' have become an important, routine and normalised part of everyday farming life (Donaldson, 2008). However, it can be argued, as Donaldson does, that such measures are 'antipolitical' in the sense that they close down the possibilities of wider debate about, for instance, the wider, pathogenic 'disease situations' (Hinchliffe et al., 2016) associated with contemporary agricultural practices. 
In this argument, which draws on Beck's concept of the risk society (Beck \& Ritter, 1992), disease is not simply something which is an external threat to human activities. Instead particular farming practices produce a disease risk which is inherent to them (Hinchliffe et al., 2013; Hinchliffe et al., 2016). Critical questions arise, therefore, concerning how farming is done, and in particular about the biosecurity implications of intensively 'enclosed' (Watts, 2000) forms of animal agriculture. Donaldson (2008) thus argues for a re-introduction of politics to discussions about biosecurity, so that such questions can be articulated and addressed by exploring modes of animal husbandry which are inherently less risky, and which might conceive and practice biosecurity in different ways. Returning to the earlier discussion of lay knowledge-practices, farmers' own situated and heterogeneous understandings of securing life, and the practices they engage in as a result, are likely to be important, even where they differ from official perspectives on how biosecurity should be 'done' (Enticott, 2008a; Hinchliffe \& Ward, 2014). For instance, Shortall et al (2018) and Naylor et al (2018) examine how different understandings of 'good farming' affect biosecurity practices, while Hinchliffe et al. (2016) examine the 'patchworked' biosecurity of pig farmers who, far from attempting to separate pigs from microbes, actively aim to create an alternative mode of biosecurity by bringing bought-in pigs into contact with the microbe-containing faeces of existing pigs, with the aim of creating a degree of herd immunity which in the longer term protects animals from more serious disease outbreaks.

For geographers, the spatial implications of biosecurity have been brought to the fore. As Donaldson (2008:1552-1553, see also Hinchliffe et al., 2013, 2016) puts it, 'Viewed from a geographical perspective, biosecurity implies the maintenance of a spatial separation between categories of biological things: those that are valued ... and those which represent a threat to the wellbeing of the valued groups'. Hinchliffe et al. (2016) draw further on Foucault to describe the emergence over time of three 'diagrams' of biosecurity, each of which describes how the issue is framed in both thought and practice, and is spatialised in terms how it separates 'good' from 'bad' life. Thus, a diagram of 'exclusion' suggests a process of banishing the sick; 'inclusion' suggests an alternative form of spatial organisation, institutionalisation and regulation associated with a process of quarantining the sick in relation to the rest of the population; and 'normalisation' implies attempts to actually manage disease 
through interventions such as vaccination which accept the constant presence of disease-causing agents while pre-empting their potential effects.

Although the diagrams are presented as an historical sequence, it is noted that they do not simply replace one another. For example, realising the third, normalising, diagram, associated with the Foucauldian concept of biopower (e.g. Foucault, 1990; 2007), might nevertheless involve elements of exclusion or inclusion. This is the case in the emergence of discourses of biosecurity in contemporary agricultural governance. Thus, biosecurity policy and the practices it requires have tended to be constructed around the establishment of spaces variously described as 'pure', 'safe' or 'secure', and separated from the 'infected nature' of contiguous 'unsafe', 'nonpurified' or 'unruly' spaces (Enticott, 2008b; Enticott \& Franklin, 2009; Mather \& Marshall, 2011). In practice, the situation is more complex: rural spaces are more differentiated, at different scales (Enticott, 2008b), and instead of being able to maintain a spatial separation between the pure and impure, or between good and bad circulations, farmers engage in a 'patching-together' of biosecurity (Hinchliffe \& Ward, 2014; Hinchliffe et al., 2016). Evoking a topological account of space, in which topographic conventions of distance are destabilised by an understanding of how entities 'distant' from each other can nevertheless be folded together into close relationship, and proximate entities can be held apart, Hinchliffe et al (2013:540, see also Hinchliffe et al., 2016) argue that 'disease and the responses to it are marked more by intense entanglements of hosts, environments and institutions than a simple geometry of fixed objects invading pure, or more or less resilient spaces'.

Taking this discussion forward, I focus on how smallholders and smallholding spaces and practices are positioned in relation to these discussions of animal health, welfare and biosecurity.

\section{Researching smallholding and biosecurity}

Four smallholder focus groups were convened between February and April 2016. Each group met once, for approximately two hours. Group meetings were held in York (referred to hereafter as the York group), Belper (Derbyshire group), Exeter (Exeter group) and Reaseheath Agricultural College (Cheshire group). Meetings 
were facilitated by the author (with the exception of the Exeter meeting), supported by an additional colleague ${ }^{3}$.

The York group was recruited by Defra and included 9 participants, 8 from the north of England and 1 from north Wales. The Exeter group was also recruited by Defra and included 6 participants from South West England. Both the Derbyshire and Cheshire groups were recruited by the author from smallholder associations, and included 9 and 7 participants respectively. Due to the recruitment process, which was dependent on either Defra or association officials, it cannot be claimed that the groups are representative of all smallholders either in England or in their areas. Indeed, as already noted there is no clear definition of smallholding, so an attempt to be representative would be problematic. Nevertheless some caution is needed. The groups were self-selected volunteers, and were likely to consist of smallholders who were particularly interested in and engaged with animal health and welfare issues, and who were more likely to be aware of legislation and regulations relevant to welfare and biosecurity. Indeed, as returned to later, reference was made during group discussions to 'other' livestock keepers who were less well-informed and were represented as posing more risks to welfare and biosecurity. However, each group was diverse and their memberships illustrated a range of perspectives, associated with (for example) different farming and non-farming backgrounds, different holding sizes and histories of involvement with smallholding, different livestock species, and different attitudes towards smallholding and their relationships with their livestock. Participants were informed that their comments, where used, would be attributed to the group, and thus individual speakers are not identified in transcripts or in subsequent reporting of the research. It is recognised that this prevents the connection of comments to individual speakers, which precludes connecting comments from a single contributor together, or representing individual identities and situations (for example, by referring to a contributor's specific background or livestock).

\footnotetext{
${ }^{3}$ I would like to thank Alice Hamilton-Webb and Emily Edwards (both of the Royal Agricultural University) for their roles in facilitating the Exeter and Belper meetings. Other meetings were supported by Defra staff.
} 
The focus groups included four main areas of discussion. First, participants introduced themselves by talking about their own smallholdings and animals, and their histories of involvement in smallholding, and the group discussed different attitudes towards smallholding and livestock. Second, the groups focused on their practices relating to the prevention and control of disease in their animals.

Participants were asked how they knew animals were ill and what they did in response, about their relationships with vets and other advisers, and about the measures they took to maintain their animals' health and welfare. Third, groups discussed issues relating to animal movements and contact between their own and others' animals. Participants talked about how they obtained new animals and the measures taken to reduce the risk of disease when animals were moved on or off their holdings. Finally, groups were asked about the different sources of information available to them relating to animal health and welfare. Meetings were audio recorded and transcribed.

Transcripts were open coded using QSR Nvivo software. Coding was influenced by specific issues raised by Defra, which included a request to focus on how smallholders knew when animals were ill and what they did in response, their use of vets, how they acquired and moved animals, and their awareness and use of different sources of information on animal health. But the process was also inductive in going beyond Defra's framing of the questions, allowing themes and concepts related to smallholding and biosecurity knowledge-practices to emerge from the data. The intention here was to allow the participants, through the focus group data, to articulate dimensions of their knowledge-practices which might engage with or counter the initial framing of the issue as one in which smallholders threatened the biosecurity of commercial agriculture. This process allowed critical interrogation of that assumption, while acknowledging that the perspectives of the smallholders themselves, as embedded in the data, were variable and not unproblematically objective. Excerpts from transcripts used in the rest of the paper are intended to represent themes derived from the coding process, support the contribution to theorisation of biosecurity as something which can be different in relation to different kinds of farming, and to articulate smallholders' own framing of knowledge-practices related to their animals. 


\section{Smallholding knowledge-practices: caring for health and biosecurity.}

In this first empirical section, I examine, first, participants' comments on how they know about and care for their animals, and second, their engagements with animal health and biosecurity. The section attends to smallholder response-ability with their animals, and to how smallholding spaces influence how smallholders attempt to piece together animal health and biosecurity.

Care, welfare and response-ability

Smallholders emphasised that welfare was central to their practices and identities. As one said,

'In my mind, [welfare] is the most important thing. If you can't look after something, you shouldn't have it.' (York)

Smallholding as a set of practices was represented as offering a capacity for humans to interact with animals in ways beneficial to the animals themselves, as well as important to how participants understood themselves as animal keepers. The speaker below, for example, argued that:

'I like the personal thing with animals. They are livestock, they're not pets, and they have an end, which is there from the start. But I still believe very strongly that animals thrive - they do - with human input. I see a lot of people flying about on quads and things like that, which I realise is necessary with these big concerns. But for me, I strongly believe part of their welfare is being among them, watching them.' (York)

An important perspective was that smallholders' animals 'thrive' due to smallholders' ability to respond, quickly and on an individual basis, to health and welfare issues. In this sense the response-ability of smallholders was emphasised, and presented as facilitating good health and welfare practices. In the comment above, for example, shepherding of large numbers of sheep using a quad bike is implicitly criticised because the speed of the machine, and the amount of land and numbers of animals the shepherd is responsible for, means they are less likely to be response-able in the 
way that smallholders can be. The scale and the mechanisation of commercial farming are presented as problematic, countering smallholding's small-scale caring practices.

This small scale, then, is bound up with practices of care and response-ability towards individual animals which are less evident in larger-scale farming.

Participants discussed this in focusing on how they engaged with their animals' health, identifying emergent illness through their close relationships with small numbers of animals. Drab-looking feathers, changes in faecal consistency and minor behavioural changes were mentioned as indicating there was a problem to respond to. The following comments responded to questions about how participants know that an animal is unwell:

'I think it just comes down to knowing your animals. As small-scale animal keepers we've got hopefully the capacity to know our animals, how what a well animal looks like so by default then anything else is an unwell animal.' (Derbyshire)

'You can spot a change in an individual sheep's character quite easily. Certainly with our sheep if they're getting sore feet, you can often tell their feet aren't right before they're showing any actual signs of head nodding or actual limping just because they're not as mobile as they normally are. I think you pick up on it much easier when you know them individually.' (Derbyshire)

Smallholders are thus involved in farming at a scale which, they argue, fosters a responsiveness to animal illness or suffering (although other research describes how commercial farmers too can be responsive to their animals in similar ways, see for example Wilkie, 2005; Shortall et al., 2018). For example, one commented that, in relation to knowing that an animal is ill, 'after a while it becomes natural that you know something's wrong with that sheep' (Cheshire). Another said that:

'It is quite instinctive sometimes. Sometimes you don't actually feel that you are looking. Like I will be doing something and then I will think, you listen or you see something and subconsciously you think "actually that's not right". But that just comes with experience ...' (Exeter) 
Although the majority of participants were new entrants to farming, they expressed the development of lay knowledge-practices associated with an affective response to being, and being intimate, with their animals.

\section{Engagements with biosecurity}

Smallholding disease knowledge-practices were associated with smallholders' attempts to prevent and prepare for disease, and hence to their engagements with biosecurity. In relation to biosecurity practices, smallholders represented in the groups were highly aware of relevant regulation. For instance, although they could or did not always fully comply (see below), they were knowledgeable regarding quarantine regulations and the maintenance of animal movement and treatment records. Similarly, they were aware of the strict regulations surrounding the feeding of waste foods (e.g. kitchen scraps) to animals, and of the requirements to notify Defra regarding certain diseases (and to comply with regulations aiming to prevent such diseases).

As discussed, crucial to both the practising of biosecurity and to the functioning of smallholdings as sites which maintain animal populations, was the necessity of both fostering and regulating circulations of animal life. Two related areas of practice provide examples: first, precautions taken when acquiring new animals, and second, how smallholding practices and micro spaces were thought about in relation to attempts to pre-empt disease transmission and effect a separation between existing 'healthy' on-farm animal populations and either sick animals or potentially risky newly-acquired animals. The limits of specifically smallholding spaces and practices, in contrast to those of larger-scale farming, are also addressed, in considering how smallholders develop pragmatic approaches to biosecurity.

Practices of acquiring animals, and moving animals on and off holdings, were inflected by differences in the perceived security of the animals' source. As suggested by this speaker, biosecurity can be something assured and certified by the professional practices associated with some sources. The speaker compares poultry sold by commercial breeding companies with those offered by alternative vendors: 
'So I think certainly with chickens, commercial egg laying chickens are amazingly good value, and unless you're in it for showing I'm very reluctant to own anything else, partly because they're healthy and vaccinated and readily available at the right price, but I would be very reluctant to buy secondhand ${ }^{4}$ ones. I'd rather have new ones just because when you get new ones they tend to come from a much larger outfit that's much more aware of biosecurity and keeping things healthy, whereas the second-hand ones are often not in such good condition.' (Derbyshire)

Taking a different perspective, another participant felt that biosecurity decreased as the distance between buyer and seller increased;

'I suppose it depends how far you are buying this animal from. If it is not too far away it is not really much of a risk. But if you are buying it from somewhere in the other part of the country or even abroad then there is a bigger risk isn't there? But then it would be quarantined anyway wouldn't it?' (Exeter)

Different topological senses are evident here, with a feeling for the second speaker that increasing distance heightens risk contrasting with the previous speaker's perspective that a vaccination certificate and knowing that animals were bred by a professional organisation was more important and bridged a geographical gap between locations, even if the site of the organisation was distant from the smallholding.

For other participants the knowledge that they had acquired of different holdings their animals might circulate between led to different responses to animal movements;

'Yes, there are certain farms ... if one of my sheep goes to that particular farm, then when it comes back, it's going into absolute solitary isolation, it's staying there for a good six weeks, and it's getting jabbed $^{5}$ for this and jabbed for that, and jabbed for everything else. Yet, there are other farms who I know run on a similar system to myself, and similar standards. If we did get a bit of a slop over, it wouldn't be a big issue'. (York)

This comment suggests there are biosecurity concerns in relation to some farms, and trust in relation to others. For the latter farms, 'slop over', suggestive of animals (and their microbes) coming into contact with other animals (and their microbes), is less of a concern. This illustrates the patching of biosecurity referred to by Hinchliffe et al. (2016), whereby total segregation of forms of life cannot be achieved in

\footnotetext{
${ }^{4}$ This is a reference to practices of either buying from smaller breeders or adopting hens 'rescued' from commercial poultry farms.

${ }^{5}$ vaccinated
} 
practice, and different kinds of response are implemented depending on the precise nature of the relationships between the actors and sites involved. Echoing Driessen's (2012) comments on approaches to welfare, here biosecurity is protean and is different in different circumstances.

Groups discussed how they practiced hygiene on their smallholding sites, and in particular the separation or quarantining of animals. This implied a process of segregating the 'clean' and the 'dirty', of using hygiene and isolation practices as a way of keeping things, including animals and microbes, in their place, as part of an 'inclusion' diagramming of (potential) disease. Further, smallholders used vaccination alongside quarantine, nesting inclusion within a 'normalising' diagram which accepts the presence of disease and implements strategies to reduce its disruption. The following participants noted their concern for biosecurity, relating this to both a precautionary approach emphasising cleanliness, and a preparedness to be able to take action in the case of a disease concern.

'So it's a mix of prevention and cure, and cleanliness as well. I make a real effort. It's easier to keep everything clean and tidy when you've got such a small quantity [of animals] than when you've got a lot. So l'd rather put the work in to making things neat, tidy and clean, particularly at lambing time, than when you've got an illness, when it takes you ten times longer to sort out, and it's more costly.' (York)

'I think the thing is to have the systems in place to whack up the level of biosecurity at the drop of a hat if there's an alarm ...You don't need to go overboard with all the - but the mechanisms are in place. So if there's any question or doubt or anything, or something's poorly or something, everything is in place to whack up the biosecurity level at the drop of a hat, literally.' (York)

For the second participant here, biosecurity has a quantitative ontological status (it can be increased, for example), and is also a tool for countering an emergent health concern. As noted above, the small scale of smallholding presented particular problems, however. This could mean noting that only one field was available, and/or that there were no suitable buildings for quarantining ill or bought-in animals. As one participant said,

I'm such a small acreage that I haven't got facilities to isolate things. That doesn't work for me so I don't do it. I ought to do it, l'd like to be able to do it but I can't.' (Derbyshire) 
Another commented on their practices as follows, suggesting a pragmatic biosecurity resulting from their dependence, like many smallholders, on the temporary use of other people's land, buildings and equipment:

'For me, it's prevention ... because I'm dependent. I use other people's buildings ... I have no control over how I use the land, which can be a bit of a problem. So I tend to do things like prevention, as I say, and lime round troughs, keeping them away from really wet bits, if possible. I don't want them getting fluke ${ }^{6}$. (York)

Animal agency and human-animal response-ability is also important here, as with the illicit animal contact noted above. Participants noted both a tendency for animals to escape from quarantine and for isolation to raise welfare concerns (e.g. stress) so that they were reluctant to impose it. The biosecurity, or otherwise, of a situation is thus a co-production of the humans and animals involved.

Expanding on this sense of a co-produced biosecurity, other inflections of a normalised disease diagram described how animals might acquire their own forms of biosecurity through their relationships with localised disease ecologies and within particular on-farm animal populations. In the following exchange, for example, practices of attempts to simply separate animals from microbes were questioned in favour of an immunological understanding of living with microbial nature and of animal bodies as able to respond to disease challenges;

Speaker 1: 'And they do create a, not an immunity but they get used to it, if you know what I mean? So they will still function.'

Speaker 2: 'But just at a lower level. And I suppose you can get that not through disease but like, a bit like worms.' (Exeter)

This echoes Hinchliffe et al's (2016) example of the patching of biosecurity on pig farms, where pigs were encouraged to develop more competent immune systems through controlled contact with 'muck' from other pigs. Speaker 2 further refers to the limits of determining what exactly is going on in their animals' bodies - for them a

\footnotetext{
${ }^{6}$ Liver fluke, a parasitic trematode worm causing liver damage in sheep.
} 
'lower level' of functioning, evident in lower productivity, could be to do with this sense of 'getting used to' the challenges posed to immune systems by microbial agents or it could be associated with other factors such as intestinal worms. For although biosecurity in relation to livestock has tended to be examined in relation to the microbes responsible for transmissible disease, it might also be considered in terms of the relationships between animals and (for instance) parasitic creatures such as worms. Responding to these, for the farmer or smallholder, requires alternative sets of practices for securing the life of their animals, in comparison to viruses or bacteria, contributing to a multiple sense of biosecurity in which several different classes of problematic agent (e.g. microbes, flukes and nematode worms) have to be simultaneously taken into account. For worms, for example, segregation practices might be less to do with isolating animals from each other, and more to do with keeping animals away from land known to be infected, a possible problem for smallholders with very limited space.

As is evident from this discussion, in smallholding spaces and practices controlling the circulation of life is problematic in ways related to the small scale at which things are being done. Disease diagrams of inclusion and normalisation are evident within a microscale topology which involves attempts to effect physical separation or distancing within a small space and to foster immunity in small populations of animals. Creating immune populations involved formal vaccination precautions, but a parallel understanding of immunity regarded it as something which could also be 'naturally' acquired through exposure to the pathogens present on a holding.

\section{Constructing hybrid knowledges: vets, smallholders and biosecurity.} In this second empirical section I explore how animal health and biosecurity are produced through the relationships between smallholders and other people. The particular focus here will be on smallholders' relationships with vets. This relationship is an important aspect of smallholding as, in contrast to many commercial farmers' acquisition of tacit knowledge through a farming background (Burton et al., 2012), many smallholders begin to acquire their knowledge about animals through relationships with key informants such as vets. The section finishes by commenting on how smallholders piece together hybrid knowledges about animal health by combining their own experience with veterinary expertise. 
Participants viewed relationships with their vets as crucial to the management of animal health. Valued relationships were evident with vets who acknowledged smallholders' specific situations. The following comments illustrate such smallholdervet relationships.

'Vets are good because they will dispense free information over the phone ... Our vet's pretty good if you ring up and say this is what's happening, they'll either say you can deal with it with this, come and get these drugs, or perhaps I ought to come and have a look. They're helping you to come to a decision ...' (Derbyshire)

'My vet, I have an awful good relationship with ... I go to one slightly further afield because he will dispense small amounts of medication. I find the cost of animal medicines is quite prohibitive, because they tend to come in huge packs.' (York)

Participants thus made extensive use of vets, although this usage tended to decrease as they gained in experience and confidence, and it varied in relation to their, and their vets', attitudes towards their animals. There was an acknowledgement, for example, that vets treated different species differently because of their perceived value. As the comments below suggest, poultry or even sheep, for example, could be regarded as of low value with some reluctance to resort to expensive veterinary treatment.

'We've found, to our cost, that calling the vet out for the sheep is usually a waste of money, but not for the cattle.' (York)

'It can be a matter of economics as well, whether it's going to cost you more than what the animal is worth to call the vet out.' (Cheshire)

In addition to the relative costliness of veterinary input, an important perspective was that vets either did not have experience of particular species, regarded smallholders as insignificant in relation to commercial farmers, or would make what the smallholders would see as a category error in assuming that their animals were regarded as 'pets' rather than 'livestock', with resulting differences in how the vet would treat both smallholder and animal. In the first case, smallholders might have species that local vets did not normally encounter, whether these were more 'exotic' 
animals, such as llamas, or even mundane ones such as chickens or pigs. As one participant said,

'With me only having four [hens], if I get an ill chicken, the farm vets don't want to talk to you because you're not on a commercial scale, and the small animal vets don't know anything about chickens.' (York)

In other cases, vets might assume that a smallholder views their animals as pets and is willing to pay for treatments on that basis. For example,

'The trouble with mixed practices ${ }^{7}$ is because people now will spend thousands of pounds on their pets, the vets, particularly ones who are recent graduates come out and they're not sure whether that animal is your pet or not. The older vets come out and look at a ewe and think that's worth $£ 90$ so you don't want to spend $£ 100$ on fixing it, but if you've got 200 more in the field it's obviously not going to be a pet, but if you've got 5 , it might be.' (Derbyshire)

The issues here might be problematic in a biosecurity regime because of the differences in and tensions between knowledges and understandings of different kinds of animal; for instance a smallholder might find it difficult to access a vet experienced in treating their particular livestock species, and/or willing to engage with keepers of small numbers of animals.

In other cases, participants discussed how their vets were willing to circumvent rules. Instances were described where vets would prescribe treatments for animals that were not licensed for that species. One participant, for example, said their vet had prescribed a drug for sheep, knowing (but not explicitly acknowledging) that it would be used with goats. Another discussed a situation relating to transporting an animal to the vet. As they told it,

'Our vet said just don't mention it [bringing a sheep to the practice] ... when I first had sheep I wanted to know how to vaccinate so they just said literally "bring the sheep down in the back of the truck". And they showed us how to do it in the car park of the vets. And I said, "What do I need to do about movements?" And he said, "That sheep was never here" ...' (Exeter)

\footnotetext{
${ }^{7}$ veterinary practices treating both farmed and companion animals
} 
In this case the need to document an animal movement and trigger a 'standstill' restriction on moving other animals was evaded in the pretence that the animal had not been moved in the first place. These examples imply an attempt to conceal a practice, or to evade restrictions, in order to effect an animal health or biosecurity outcome that would have been more difficult otherwise. Here, vets and smallholders contrived a pragmatic biosecurity which nevertheless contravened regulations.

Finally in this section, it was clear that in relation to animal health and biosecurity, smallholders were active participants in co-producing knowledge-practices with their vets, not simply passive recipients of veterinary expertise. Smallholders gained in experience and confidence, and attended training courses, meaning that they relied less on their vets over time. As one put it, 'You find that you call the vet out to begin with quite a lot and then you learn from the vet' (Cheshire). Another, in more detail, said;

'... a big part is being honest with yourself about where your knowledge ends, and not fiddling about with something in the hope that you're going to make it better. You either do know what's wrong, and you've seen it before and you've got the kit to treat it, or you don't know. You don't fiddle about ... and then say "oh this isn't working" and then take it to the vet's. Everybody in here will be at a different level. I would treat a sheep for something which somebody else would take to the vet's because I've seen it before ... But also work with your vets to make sure you've got a good health plan in place; an actual written health plan.' (York)

In comments such as these, the production of animal health and biosecurity is presented as, in the long term, a hybrid piecing together of smallholders' lay and vets' expert knowledges. Veterinary expertise informs smallholder knowledgepractices during consultations, and becomes formally integrated into smallholding health and biosecurity via the health plans (setting out a disease prevention and treatment programme) which can be seen as part of a normalisation disease diagram, pre-empting actual health and disease problems in a particular smallholding space.

\section{Emerging politics of agricultural biosecurity: contesting smallholding and commercial farming.}


This final empirical section explores relationships between smallholders and commercial farmers. It suggests that there is a politics to these relationships evident in contrasting representations of smallholding and commercial farming identities and practices. Focusing on smallholders' perspectives, the section looks first at how they depend on and learn from neighbouring commercial farmers. Indeed, in their 'patching' of biosecurity such relationships might be necessary. Second, however, the section explores alternative representations of some farmers, and commercial farming as a set of practices, which figure them (rather than smallholders and smallholding) as fostering a bio-insecure disease situation in a heterogeneous farming topology. Acknowledging the politics of this situation represents the farmers as, in Enticott's (2008a) terms, candidates for bioinsecurity and health risks, repositioning smallholders as effecting 'better' ways of responding to and caring for animals. As participants said, 'in some respects we are better placed to give our animals perhaps higher welfare standards' (Derbyshire), and 'I think it's interesting the term 'hobby farmer' was mentioned before, it's a pejorative term in commercial farming, the concept is that we're all harbouring disease and allow it to get into the commercial flock. Really I think the reflection here is that it's just the other way round' (York).

First then, there was a perspective that acknowledged that smallholders and their animals benefitted from immediate practical help from a neighbouring farmer, as the comments below illustrate:

'If we're round lambing time and we've got any potential issues we'll be straight on to the farmer to say this is what's happening. We had one that had a calcium deficiency last year and he was around within five minutes ... Yes he said this is really urgent so he came straight round with his calcium ... he did it all for us.' (Derbyshire)

'The farmers nearby have been very supportive to us. We're fairly new to keeping cattle, and with only two we haven't got the necessary kit when it comes to TB testing time. So they've been very, very good about helping us and lending us stuff.' (Derbyshire)

Certainly this suggests that in some circumstances smallholder animal health and biosecurity is supported by advice and practical help from farmers. But in several ways participants articulated how commercial farmers and farming can instead be 
represented as creating risk and threatening biosecurity. I outline three dimensions to this.

First, participants contrasted their own desire to learn, and anxiety to do things properly, with some farmers' lack of knowledge. Thus one said;

'.. if you go and ask the large commercial farmer down the road about it, often the answer you get doesn't imply they actually know anything about it at all ... It seems like a lot of their practice is just done because that's what they did last year and it didn't do anything wrong rather than because there's an understanding of what they're doing and why.' (Derbyshire)

This complements views expressed below, where participants argue that it is smallholders who are more likely to be well-informed and to implement biosecurity measures and good practice. One smallholder who was preparing a vaccination plan with their vet, reported the vet as saying 'that's a good idea, it'd be nice if all farms had a plan for their vaccinations and worming so that everybody's complying with best practice' (Derbyshire). Others said, for example, that;

'I think smallholders are very much governed by larger farm practices as well. I mean I feel that smallholders generally are worried about getting into trouble so we tend to follow guidelines.' (Exeter)

'... because a lot of [smallholders] have come from perhaps more academic backgrounds or worked in other careers, we're in an excellent position to really tap into that knowledge that's out there in the veterinary world $\ldots$ by keeping up to speed with those things, and working closely with your vet, you can really keep on top of health and welfare issues, so they don't actually ever become an issue on your holding ... You've got biosecurity, when [the farmer] down the road, is still saying, "oh that's a lot of nonsense".' (York)

The arguments made here resonate with research with commercial farmers and vets (Shortall et al., 2018) which suggests that some of the stockmanship practices exhibited by commercial cattle farmers from 'traditional' farming backgrounds can increase biosecurity risks, while those practices acquired by new entrants to farming, who exhibit attitudes influenced by previous non-farming experiences, can enhance biosecurity. 
Second, referring back to disease diagrams emphasising the spatial segregation of groups with different health status, some smallholders described the (bio)insecure nature of some farmers' regulation of the movement of their animals.

'For us [isolation] is a tiny bit pointless because our neighbouring farmer kind of accidentally grazes half our field sporadically when his sheep push through the fence daily. With the best will in the world we've probably got a much bigger infection risk from all the sheep that have nothing to do with our flock.' (Derbyshire)

'We have got our isolation unit but it is pointless ... our next door buys in from market and our stuff is all fenced in but his isn't fenced ... so we will quite often find that one of his ewes has jumped in with ours or we get orf ${ }^{8}$ from his orf ram going nose to nose with our ram. And of course then it is in the ground, so now we have to vaccinate.' (Exeter)

In these cases again, recalling earlier reference to 'slopping over' boundaries, it is commercial farmers and their practices and animals which are represented as risking the health and biosecurity of smallholdings. Smallholders' efforts here can be seen as part of an exclusion diagram whereby attempts are made to keep the potentially risky animals of their neighbours at a distance, and yet where smallholders' biosecurity measures are countered by their neighbours' practices.

Third, and extending the argument from the last section that some degree of skirting rules and 'patching' biosecurity are likely outcomes of, in practice, simply trying to make things work in complex circumstances, participants discussed ways in which expectations relating to biosecurity were circumvented or ignored within commercial farming. As the comments below illustrate, this was experienced by smallholders in their relations with neighbours and with their use of specialist contractors. Here, animals and equipment circulate in ways which transgress attempts to make life safe, yet this is accepted because the alternative is to prevent the vital flows which constitute farming.

' $\ldots$ if one of the sheep jumps over the fence into the neighbour's field are you really going to go round to his yard when he's just loading cattle for his biggest sale of the year and say "one of my ewes jumped over there. There's the movement licence. You can't take anything off for six days"? You'd be

\footnotetext{
${ }^{8}$ A viral skin disease
} 
shot on the spot, wouldn't you? Of course you don't. You say "One of my ewes is over. I'll pop round and get it tomorrow", and nobody says anything' (York)

Speaker 1: 'I can't say [biosecurity's] ever come up in any conversation I've ever heard in our area. People use contractors all the time. There's no biosecurity that I'm aware of.'

Speaker 2: 'But there should be. If your sheep scanner ${ }^{9}$ has just come from a farm ten miles away, and his scanning trailer is covered in filth, and he's coming straight onto your farm with it covered in filth, if you say to him "look you've got to wash that at the gate", he'll say, "well, on your bike mate, I'm not coming to do your sheep any more".' (York)

These comments suggest that within the politics of farming situations, smallholders are unable to counter practices and circulations associated with commercial farming, seen as risky but engaged in because fully complying with practices intended to assure biosecurity is simply impractical (see Singleton, 2010 for a similar example in commercial farming).

Participants, then, represented themselves as in important ways less of a risk to animal health than at least some commercial farmers. As one said, 'there'll be rogues in the commercial [sector] and when these diseases have broken out they've all come from commercial people ... I just don't see that smallholders form a risk of any measurable amount' (Cheshire).

It is important, however, not to reduce this discussion to a simplistic binary of smallholders versus commercial farmers, especially given the diversity of both categories. Focus group participants did not simply either romanticise smallholding practices or condemn farmers, but recognised a diversity of good and bad biosecurity and welfare practices within each category. The heterogeneity of smallholder identities and practices was acknowledged by focus group participants in comments which constructed 'other', less well informed or intentioned smallholder groups. For example, one said that 'You get the occasional smallholder who ... hasn't got a clue and gives us all a bad name' (Cheshire). Similarly, in a discussion of feeding kitchen waste to pigs and poultry, when one smallholder said that 'you don't feed stuff that's been in a human kitchen to an animal ... It's well established

\footnotetext{
${ }^{9}$ Ewes are scanned to confirm pregnancy and lamb numbers
} 
and I don't think anyone would consider doing that', another responded that 'I'm sure some people do' (Cheshire). This recognition that not all smallholders act as the ones in the group do adds further complexity to the politics of agricultural biosecurity and animal welfare in indicating divisions and tensions which might be articulated between different groups of (in this case) smallholders, and are associated with perceptions and moral judgements concerning other groups' knowledges, skills, practices and suitability to keep animals.

\section{Conclusions}

Smallholders and smallholding can be represented as associated with particularly risky entanglements of farm animal and disease vector life; they can be viewed as problematically pathological (Hinchliffe et al., 2016) in themselves, and threatening commercial farming. Indeed, as noted, the focus groups acknowledged that some smallholders were potentially problematic in terms of animal welfare and biosecurity. However, the perspective that smallholders are necessarily ignorant and risky amateurs is challenged by alternative views that emphasise the immanent pathology of commercial farming and urge that smallholder knowledge-practices allow for potentially greater animal care, biosecurity and response-ability. Participants in this study thus engaged in a politics of biosecurity which was resistant to simplistic representations of themselves and of commercial farming, and which emphasised multiple modes of being bio(in)secure in heterogeneous rural and agricultural spaces. They drew attention to multiple potential animal care and biosecurity knowledge-practices, including those involving circumvention of official rules, as different ways of trying to secure life in difficult circumstances.

Hinchliffe et al. (2016) refer to an early perspective on biosecurity as a problem of 'the forest edge' (p.9), implying a threat associated with a wild unknown on the borders of spaces and practices that can be controlled. While more recently bio(in)security has become seen more in terms of a concern with diseases immanent to particular socio-technical (agricultural) systems, the imaginary of the forest edge remains powerful. As mentioned above, smallholders, and the perception that their practices are amateurish and unruly in comparison to commercial farmers, might be seen as equivalent to a metaphorical forest edge, yet problematically spatialised in the sense that smallholders are not spatially separate from, or on the edge of, 
commercial farming landscapes, but are embedded within and contribute to more heterogeneous geographies of agriculture. Thus, within the topologies of farming, smallholding's small scale is amplified to become represented as a disproportionately large-scale threat to farming more widely. Smallholding is thus a problematic case. It exemplifies the social production of scale and space (e.g. Marston, 2000), as its 'smallness' is topologically transcended by a sense of its threat to large-scale commercial farming. Its agricultural marginality is confounded by its embeddedness within farming landscapes and within the circulations of bodies, microbes, equipment, knowledge and so on which constitute agriculture at all scales. It can represent alternatives to, and critiques of, commercial agriculture while remaining intimately related to mainstream farming practice. It would thus be interesting to consider similar issues in relation to other agricultural forms which might be viewed as particularly 'risky' in their circulations of humans and nonhumans, such as community or care farms. It would also be of interest to further consider commercial farmers' perspectives on smallholders, developing the perspectives articulated in existing research (e.g. Enticott, 2008a; Naylor et al., 2018) in which smallholders are represented as a biosecurity threat, to examine more carefully situations such as those noted in this paper where relationships involve the exchange of knowledge, practical help and equipment between smallholders and commercial farmers. In these situations the construction of smallholders and smallholding simply as a threat appears reductive and problematic, and exploring further how understandings of this 'threat' are produced and circulate would be valuable, especially in the context of the alternative representations of smallholder-farmer relationships by smallholders. Further exploration of how these issues relate to different livestock species would also be valuable, given the comments made at the start of this paper about the focus of existing literature and concern on threats to intensively-farmed pigs and poultry, and the emergent focus in this paper on more extensively-farmed animals.

In these ways the example of smallholding reflects Hinchliffe and Lavau's (2013) commentary on how, in addition to considering the differentiated spaces of farming, there is a need to pay attention to differentiated knowledge-practices, and in particular to those 'knowledges, lives and practices which retain an outsider-ness despite being integral to security' (p.262). This acknowledges the potential for some 
circulations to disrupt others, as was suggested in representations of smallholders as a threatening presence in wider agricultural landscapes. And yet this representation is challenged by smallholders themselves. The scale and intensity of commercial farming, contrasted with smallholding, meant that instead of smallholders being an internalised 'forest edge' in the agricultural topology of rural spaces, they could be represented as positing an alternative 'model' for how to effect biosecure and response-able animal care:

'Because we are smallholders, we check them all the time. So we see it quickly, we treat it and we deal with it. I think quite often with farmers it is slightly more different in terms of he has got hundreds of sheep all over the place, they don't get checked regularly. So when he finds them they are dead. But he won't know why, he won't know what the symptoms are.' (Exeter).

An important dimension of this is to acknowledge that, within smallholding and commercial farming, animals become different entities in several ways. Clearly, differences between species matter but in addition animals of even the same species are represented differently by smallholders and commercial farmers, they become constituted, both physically and in terms of their subjectivities, differently because of the different human-nonhuman relationships they are part of, and their agency and capacities (for example to escape, to circulate, to be active if unintentional contributors to welfare or biosecurity outcomes) are produced differently in different farming scales. The specific nature of what it is to be an animal on a smallholding is thus significant to the debate about the risks (or otherwise) of smallholding spaces and practices. Exploring this contested position of smallholding, and its potentially alternative circulations of knowledge-practices and organisms, thus contributes to a more nuanced understanding of differentiation, but also connectedness, within farming and the practising of agricultural biosecurity.

\section{Acknowledgements}

I would like to thank Christopher Bear and three anonymous reviewers of a previous version of this paper for their thoughtful and constructive comments.

\section{References}


Anderson, B. (2010) Preemption, precaution, preparedness: Anticipatory action and future geographies. Progress in Human Geography, 34(6), 777-798.

Beck, U. \& Ritter, M. (1992) Risk society - towards a new modernity. Translated from English by.Sage Publications.

Bingham, N., Enticott, G. \& Hinchliffe, S. (2008) Biosecurity: spaces, practices, and boundaries. Environment and Planning A, 40(7), 1528-1533.

Brown, K. \& Dilley, R. (2012) Ways of knowing for response-ability in more-than-human encounters: the role of anticipatory knowledges in outdoor access with dogs. Area, 44(1), 37-45.

Buller, H. (2009) Agricultural animal welfare, in N, K. R. a. T. (ed), International Encyclopedia of Human Geography. Oxford: Elsevier, 127-132.

Buller, H. (2013) Individuation, the Mass and Farm Animals. Theory Culture \& Society, 30(7-8), 155175.

Buller, H. \& Morris, C. (2003) Farm animal welfare: A new repertoire of nature-society relations or modernism re-embedded? Sociologia Ruralis, 43(3), 216-+.

Buller, H. \& Roe, E. (2018) Food and Animal Welfare. London: Bloomsbury.

Burton, R. J. F., Peoples, S. \& Cooper, M. H. (2012) Building 'cowshed cultures': A cultural perspective on the promotion of stockmanship and animal welfare on dairy farms. Journal of Rural Studies, 28(2), 174-187.

Butler, D. \& Holloway, L. (2016) Technology and Restructuring the Social Field of Dairy Farming: Hybrid Capitals, 'Stockmanship' and Automatic Milking Systems. Sociologia Ruralis, 56(4), 513-530.

Capoccia, S., Masters, M. \& Risser, S. (2018) Urban Chickens as a Pathway for Human Illness: An Examination of Knowledge, Behavior and Risk. Urban Science, 2(1), 25.

Clarke, C. A. \& Knights, D. (2018) Practice makes perfect? Skillful performances in veterinary work. Human Relations.

Collier, S. J., Lakoff, A. \& Rabinow, P. (2004) Biosecurity: towards an anthropology of the contemporary. Anthropology today, 20(5), 3-7.

Convery, I., Bailey, C., Mort, M. \& Baxter, J. (2005) Death in the wrong place? Emotional geographies of the UK 2001 foot and mouth disease epidemic. Journal of Rural Studies, 21(1), 99-109. 
Correia-Gomes, C., Henry, M. K., Auty, H. K. \& Gunn, G. J. (2017) Exploring the role of small-scale livestock keepers for national biosecurity-The pig case. Preventive Veterinary Medicine, 145, 7-15.

Crouch, D. (1997) 'Others' in the rural: leisure practices and geographical knowledge, in Milbourne, P. (ed), Revealing Rural Others: representation, power and identity in the British countryside. London: Pinter, 57-74.

Donaldson, A. (2008) Biosecurity after the event: risk politics and animal disease. Environment and Planning A, 40(7), 1552-1567.

Driessen, C. (2012) Farmers Engaged in Deliberative Practices; An Ethnographic Exploration of the Mosaic of Concerns in Livestock Agriculture. Journal of Agricultural \& Environmental Ethics, 25(2), 163-179.

Enticott, G. (2008a) The ecological paradox: social and natural consequences of the geographies of animal health promotion. Transactions of the Institute of British Geographers, 33(4), 433-446.

Enticott, G. (2008b) The spaces of biosecurity: prescribing and negotiating solutions to bovine tuberculosis. Environment and Planning A, 40(7), 1568-1582.

Enticott, G. (2009) Introduction to the Theme Section: Rural Sociology and Animal Disease. Sociologia Ruralis, 49(4), 327-329.

Enticott, G. \& Franklin, A. (2009) Biosecurity, Expertise and the Institutional Void: The Case of Bovine Tuberculosis. Sociologia Ruralis, 49(4), 375-393.

Enticott, G. \& Vanclay, F. (2011) Scripts, animal health and biosecurity: The moral accountability of farmers' talk about animal health risks. Health Risk \& Society, 13(4), 293-309.

Foucault, M. (1990) The History of Sexuality, Volume 1: An Introduction. Harmondsworth: Penguin.

Foucault, M. (2007) Security, territory, population. Lectures at the Collège de France 1977-78.

Translated from English by. Basingstoke: Palgrave MacMillan.

Garlick, B. (2015) Not all dogs go to heaven, some go to Battersea: sharing suffering and the 'Brown Dog affair'. Social \& Cultural Geography, 16(7), 798-820.

Gasson, R. (1982) Part-time farming in Britain: research in progress. GeoJournal, 6, 355-357.

Gasson, R. (1986) PART TIME FARMING STRATEGY FOR SURVIVAL. Sociologia Ruralis, 26(3-4), 364376. 
Gillespie, A. V., Grove-White, D. H. \& Williams, H. J. (2015) Husbandry, health and biosecurity of the smallholder and pet pig population in England. Veterinary Record, 177(2), 47.

Greenhough, B. \& Roe, E. (2010) From ethical principles to response-able practice. Environment and Planning D: Society and Space, 28, 43-45.

Halfacree, K. (1997) Contrasting roles of the post-productivist countryside: a postmodern perspective on counterurbanisation, in Cloke, P. a. L., J (ed), Contested Countryside Cultures. London: Routledge, 70-93.

Haraway, D. (2008) When Species Meet. London: University of Minnesota Press.

Hinchliffe, S. (2001) Indeterminacy in-decisions - science, policy and politics in the BSE (Bovine Spongiform Encephalopathy) crisis. Transactions of the Institute of British Geographers, 26(2), 182204.

Hinchliffe, S., Allen, J., Lavau, S., Bingham, N. \& Carter, S. (2013) Biosecurity and the topologies of infected life: from borderlines to borderlands. Transactions of the Institute of British Geographers, 38(4), 531-543.

Hinchliffe, S. \& Bingham, N. (2008) Securing life: the emerging practices of biosecurity. Environment and Planning a-Economy and Space, 40(7), 1534-1551.

Hinchliffe, S., Bingham, N., Allen, J. \& Carter, S. (2016) Pathological Lives: Disease, Space and Biopolitics.

Hinchliffe, S. \& Lavau, S. (2013) Differentiated circuits: the ecologies of knowing and securing life. Environment and Planning D-Society \& Space, 31(2), 259-274.

Hinchliffe, S. \& Ward, K. J. (2014) Geographies of folded life: How immunity reframes biosecurity. Geoforum, 53, 136-144.

Holloway, L. (2000) 'Hell on earth and paradise all at the same time': the production of smallholding space in the British countryside. Area, 32(3), 307-315.

Holloway, L. (2001) Pets and protein: placing domestic livestock on hobby-farms in England and Wales. Journal of Rural Studies, 17(3), 293-307.

Holloway, L. (2002) Smallholding, hobby-farming, and commercial farming: ethical identities and the production of farming spaces. Environment and Planning A, 34(11), 2055-2070.

Holloway, L. (2005) Aesthetics, genetics, and evaluating animal bodies: locating and displacing cattle on show and in figures. Environment and Planning D-Society \& Space, 23(6), 883-902. 
Holloway, L. (2007) Subjecting cows to robots: farming technologies and the making of animal subjects. Environment and Planning D-Society \& Space, 25(6), 1041-1060.

Holloway, L., Bear, C. \& Wilkinson, K. (2014) Robotic milking technologies and renegotiating situated ethical relationships on UK dairy farms. Agriculture and Human Values, 31(2), 185-199.

Hovorka, A. (2008) Transspecies urban theory: chickens in an African city. Cultural Geographies, 15(1), 95-117.

Kloppenburg, J. (1991) SOCIAL-THEORY AND THE DE RECONSTRUCTION OF AGRICULTURAL SCIENCE LOCAL KNOWLEDGE FOR AN ALTERNATIVE AGRICULTURE. Rural Sociology, 56(4), 519-548.

Lynn, W. (1998) Contested Moralities: animals and moral value in the Dear/Symanski debate. Ethics, Place and Environment, 1, 223-242.

Marston, S. A. (2000) The social construction of scale. Progress in Human Geography, 24(2), 219-242.

Mather, C. \& Marshall, A. (2011) Biosecurity's unruly spaces. Geographical Journal, 177, 300-310.

McMichael, M. (2009) A food regime genealogy. The Journal of Peasant Studies, 36(1), 139-169.

Miele, M. (2016) The making of the brave sheep ... or the laboratory as the unlikely space of attunement to animal emotions. Geohumanities, 2(1), 58-75.

Morris, C. (2006) Negotiating the boundary between state-led and farmer approaches to knowing nature: An analysis of UK agri-environment schemes. Geoforum, 37(1), 113-127.

Munton, R. J., Whatmore, S. J. \& Marsden, T. K. (1989) PART-TIME FARMING AND ITS IMPLICATIONS FOR THE RURAL LANDSCAPE - A PRELIMINARY-ANALYSIS. Environment and Planning A, 21(4), 523536.

Murdoch, J. \& Clark, J. (1994) SUSTAINABLE KNOWLEDGE. Geoforum, 25(2), 115-132.

Naylor, R., Hamilton-Webb, A., Little, R. \& Maye, D. (2018) The 'Good Farmer': Farmer Identities and the Control of Exotic Livestock Disease in England. Sociologia Ruralis, 58(1), 3-19.

Palmer, C. (2001) "Taming the wild profusion of existing things"? A study of Foucault, power, and human/animal relationships. Environmental Ethics, 23(4), 339-358.

Philo, C. \& Wilbert, C. (eds) (2000) Animal Spaces, Beastly Places: New geographies of human-animal relations. London: Routledge. 
Polanyi, M. (1966) The Tacit Dimension. New York: Doubleday.

Porphyre, T., Correia-Gomes, C., Chase-Topping, M. E., Gamado, K., Auty, H. K., Hutchinson, I., Reeves, A., Gunn, G. J. \& Woolhouse, M. E. J. (2017) Vulnerability of the British swine industry to classical swine fever. Scientific Reports, 7.

Proctor, A., Donaldson, A., Phillipson, J. \& Lowe, P. (2012) Field expertise in rural land management. Environment and Planning $A, 44(7), 1696-1711$.

Riley, M. (2008) Experts in their fields: farmer-expert knowledges and environmentally friendly farming practices. Environment and Planning A, 40(6), 1277-1293.

Riley, M. (2011) 'Letting them go' - Agricultural retirement and human-livestock relations. Geoforum, 42(1), 16-27.

Robinson, P. A. (2017a) Farmers and bovine tuberculosis: Contextualising statutory disease control within everyday farming lives. Journal of Rural Studies, 55, 168-180.

Robinson, P. A. (2017b) Framing bovine tuberculosis: a "political ecology of health' approach to circulation of knowledge(s) about animal disease control. Geographical Journal, 183(3), 285-294.

Shortall, O., Sutherland, L. A., Ruston, A. \& Kaler, J. (2018) True Cowmen and Commercial Farmers: Exploring Vets' and Dairy Farmers' Contrasting Views of "Good Farming' in Relation to Biosecurity. Sociologia Ruralis, 58(3), 583-603.

Singleton, V. (2010) Good farming: control or care?, in Mol, A., Moser, I. \& Pols, J. (eds), Care in practice: on tinkering in clinics, homes and farms. Piscataway, New Jersey: Transaction, 235-256.

Tsouvalis, J., Seymour, S. \& Watkins, C. (2000) Exploring knowledge-cultures: precision farming, yield mapping, and the expert-farmer interface. Environment and Planning A, 32(5), 909-924.

Urbanik, J. (2012) Placing animals: an introduction to the geography of human-animal relations. Lanham, Maryland: Rowman and Littlefield.

Vanclay, F. \& Enticott, G. (2011) The Role and Functioning of Cultural Scripts in Farming and Agriculture. Sociologia Ruralis, 51(3), 256-271.

Watts, M. (2000) Afterword: Enclosure, in C, P. C. a. W. (ed), Animal Spaces, Beastly Places. London: Routledge, 292-304.

Whatmore, S. J. (2002) Hyrbid geographies: natures cultures spaces. London: Sage. 
Wilkie, R. (2005) Sentient commodities and productive paradoxes: the ambiguous nature of humanlivestock relations in Northeast Scotland. Journal of Rural Studies, 21(2), 213-230.

Williams, H. \& Gillespie, A. (2013) Husbandry and healthcare of pet and smallholder pigs. Veterinary Record, 173(14), 352.

Wolch, J. \& Emel, J. (eds) (1998) Animal Geographies: Place, Politics and Identity in the NatureCulture Borderlands. London: Verso.

Woods, A., Bresalier, M., Cassidy, A. \& Mason Dentinger, R. (2018) One health and its histories: animals and the shaping of modern medicine. London: Palgrave. 